\title{
SUPLEMENTAÇÃO DE MANANOLIGOSSACARÍDEOS (MOS) E UMA MISTURA DE ALUMINOSILICATOS NA QUALIDADE DAS FEZES DE CÃES ADULTOS
}

\section{Supplementation of mannanoligosaccharides (MOS) and aluminossilicate mix on fecal quality of adult dogs}

\author{
FÉLIX, A.P. ${ }^{1}$; ZANATTA, C.P. ${ }^{2}$; BRITO, C.B.M. ${ }^{3}$; MURAKAMI, F.Y. ${ }^{1}$; FRANÇA, M.I. ${ }^{4}$; \\ MAIORKA, A. ${ }^{5}$; FLEMMING, J.S. ${ }^{5}$
}

${ }^{1}$ Zootecnista, MSc. - Programa de Pós-graduação em Ciências Veterinárias - UFPR.

${ }^{2}$ Graduanda em Zootecnia - UFPR.

${ }^{3}$ Zootecnista, MSc. - Laboratório de Nutrição Animal - UFPR.

${ }^{4}$ Médico Veterinário, MSc. - Laboratório de Nutrição Animal - UFPR.

${ }^{5}$ Departamento de Zootecnia - UFPR.

Endereço para correspondência: Ananda Portella Félix: ananda_felix@yahoo.com.br

\section{RESUMO}

O presente estudo teve como objetivo avaliar as características das fezes de cães alimentados com três dietas: controle, com suplementação de 0,10\% de MOS e com 0,25\% de uma mistura de aluminossilicatos. Foram utilizados 15 cães adultos da raça Beagle. O experimento seguiu delineamento inteiramente casualizado, em parcela subdividida no tempo, com cinco dias de colheita de dados e cinco cães recebendo cada tratamento, totalizando 25 observações por tratamento. As dietas foram oferecidas por um período de adaptação de 25 dias seguidos de cinco dias de colheita total de fezes. As médias foram comparadas pelo teste Tukey-Kramer $(\mathrm{P}<0,05)$. Os cães suplementados com a mistura de aluminossilicatos apresentaram maior teor de matéria seca $(40,40 \%)$ e maior escore das fezes $(4,00)$, em relação às outras dietas. A adição de MOS na dieta resultou em valores intermediários para matéria seca $(37,91 \%)$ e escore fecal $(3,64)$, enquanto os cães alimentados com a dieta controle apresentaram fezes com menor teor de matéria seca $(35,72 \%)$ e escore $(2,84)$. O teor de amônia foi menor nas fezes dos cães alimentados com as dietas contendo a mistura de aluminossilicatos $(0,25 \%)$ ou MOS $(0,25 \%)$, em relação à dieta controle $(0,29 \%)$. 0 $\mathrm{pH}$ e a quantidade de fezes excretadas não diferiram entre os tratamentos. A adição de aluminossilicatos ou MOS na dieta melhora a qualidade das fezes dos cães.

Palavras-chave: argila, consistência das fezes, oligossacarídeos.

\begin{abstract}
This study aimed to evaluate fecal characteristics of dogs fed three diets: control, supplemented with $0.10 \%$ MOS and with $0.25 \%$ aluminossilicate mix. Fifteen adult Beagle dogs were used. The trial followed a completely randomized desing, in split-plot, with five days of sampling collection and five dogs feeding each treatment, in a total of 25 observations per treatment. Diets were offered for 25 days adaptation period followed by a five days total feces collection period. Tukey-Kramer's test was used to compare the means. Dogs supplemented with aluminossilicate mix in diet had higher fecal dry matter content (40.40\%) and higher fecal score (4.00) than the other diets. The supplementation of MOS resulted in medium dry matter content $(35.72 \%)$ and fecal score (3.64), while dogs fed the control diet showed lower fecal dry matter content $(35.72 \%)$ and score (2.84). The concentration of ammonia was lower in feces of dogs fed diets with aluminossilicate mix $(0.30 \%)$ or MOS $(0.30 \%)$, than on the control diet $(0.35 \%)$. The diets did not differ about $\mathrm{pH}$ and fecal output. The inclusion of aluminossilicate or MOS positively influenced fecal quality of dogs.
\end{abstract}

Key words: clay, fecal consistency, oligosaccharides. 


\section{INTRODUÇÃO}

Assim como a avaliação da digestibilidade do alimento, a qualidade das fezes produzidas também é importante aspecto a ser considerado na nutrição de cães. Os proprietários dos animais buscam alimentos que proporcionem fezes mais consistentes e de menor odor, facilitando a higienização do ambiente nos quais os cães são criados.

A produção de fezes mais firmes e secas pelos cães pode ser resultante da ingestão de alimentos de alta digestibilidade, produzidos com ingredientes de boa qualidade, com moderado teor de fibras e bem processados. Entretanto, em formulações com alta inclusão de farelos vegetais, como em alimentos econômicos, e/ou no caso de alimentos para cães de raças grandes, os quais geralmente apresentam fezes mais úmidas, pode-se empregar aditivos, como os prebióticos, os quais são moduladores da microbiota intestinal ou as argilas, que formam um complexo com a água, tendo ação antidiarréica e impedindo que esta permaneça livre nas fezes excretadas.

As argilas são sais minerais insolúveis e pertencem à família dos silicatos (silicatos de alumínio) (Madkour et al., 1993). Sua estrutura básica é tetraédrica: quatro átomos de oxigênios ao redor de um átomo de silício ou alumínio. As argilas mais utilizadas são zeolitas, bentonita, esmectita e sepiolita. A capacidade adsorvente destas substâncias é devida à sua molécula aberta que possui o cátion sódio $\left(\mathrm{Na}^{+}\right)$predominante. O sódio fica solvatado às moléculas de água, aumentando várias vezes o seu volume inicial, o que leva à formação de um colóide, melhorando a consistência das fezes (Ferreira et al., 2005).

Os mananoligossacarídeos (MOS) são oligossacarídeos derivados das paredes de leveduras, que não são hidrolisados pelas enzimas digestivas do intestino delgado, sendo moderadamente fermenta- dos no cólon por Lactobacillus spp. e Bifidobacterium spp (Flickinger et al., 2000).

Os MOS apresentam a capacidade de modular o sistema imunológico e a microbiota intestinal, bloqueiam a aderência das bactérias patogênicas ao ocupar os sítios das células epiteliais da mucosa do intestino (exclusão competitiva) e induzem a ativação dos macrófagos, saturando os receptores de manose das glicoproteínas da superfície celular (Macari e Maiorka, 2000; Strickling et al., 2000). Em função deste efeito modulador da microbiota intestinal, os MOS podem contribuir para a saúde intestinal e, por conseguinte para a melhoria da qualidade das fezes dos cães.

O objetivo do presente estudo foi avaliar as características das fezes de cães suplementados com uma mistura de aluminossilicatos ou MOS na dieta

\section{MATERIAL E MÉTODOS}

Foram utilizados 15 cães adultos (quatro anos de idade), machos e fêmeas da raça Beagle, sadios, vacinados e desverminados, com peso médio de 13,40 $\pm 1,73 \mathrm{~kg}$, procedentes do canil do Laboratório de Estudos de Nutrição Canina - LENUCAN, da Universidade Federal do Paraná - UFPR.

Foram avaliadas três dietas: controle, com adição de $0,25 \%$ de uma mistura de aluminossilicatos e com adição de $0,10 \%$ de MOS. A mistura de aluminossilicatos ou o MOS foi adicionada a $300 \mathrm{ml}$ de óleo de soja e misturados a uma ração seca extrusada para cães adultos em misturador " $Y$ " por 15 minutos. Os ingredientes e a composição química da dieta estão apresentados na Tabela 1.

O experimento seguiu delineamento inteiramente casualizado em parcela subdividida no tempo (parcela: tratamento e subparcela: dias), com cinco dias de 
já que em concentrações extremamente altas ou baixas é possível que os AGCC contribuam para o aumento do teor de água nas fezes (Herschel et al., 1981).

\section{CONCLUSÕES}

A inclusão de aluminossilicatos na dieta melhora a qualidade das fezes dos cães, por meio da redução do teor de umidade $e$ amônia fecal. A suplementação com MOS também contribui para a produção de fezes mais consistentes e com menor teor de amônia, embora com efeito menos pronunciado que os aluminossilicatos quanto a consistência das fezes.

\section{REFERÊNCIAS}

ASSOCIATION OF THE OFFICIAL ANALITICAL CHEMISTS - AOAC. Official and tentative methods of analysis, 16.ed. Arlington, Virginia: AOAC International, 1995.

DELBECQUE, G. Les argiles en la alimentation animale. In: ANNALES DU SYMPOSIUM ALIMENTATION ANIMALE ET SANTE PUBLIQUE, Anais... Alfort, 1995.

FERREIRA, A.C.K.; ALFARO, D.M.; SILVA, L.C.C.; ROMANI, F.; LOURENÇO, M.C.; VARGAS, F.; SANTIN, E. O uso de aluminossilicato (Silvet ${ }^{\circledR}$ ) como adjuvante na melhora do aspecto das fezes e desempenho das aves. Archives of Veterinary Science, Curitiba, v.10, n.1, p.117-122, 2005.

FIORAMONTI, J.; THEODOROU, V.; BUENO, L.; HACHET, T. Absortine and motor components of the antidiarrhoesl action of loperamide a in vivo study in pigs. Journal of Gastroenterology and Hepatology, v.40, p.30-35, 1991.

FLICKINGER, E. A., WOLF, B. W., GARLEB, K. A., CHOW, J., LEYER, G. J., JOHNS, P. W. \& FAHEY, G. C., JR. Glucose-based oligosaccharides exhibit different in vitro fermentation patterns and affect in vivo apparent nutrient digestibility and microbial populations in dogs. Journal of Nutrition v.130, p.1267-1273, 2000.
HERSCHEL, D. A., ARGENZIO, R. A., SOUTHWORTH, M.; STEVENS, C. E. Absorption of volatile fatty acid, $\mathrm{Na}$, and $\mathrm{H}_{2} \mathrm{O}$ by the colon of the dog. American Journal of Veterinary Research. n.42, p.1118-1124, 1981.

MACARI, M.; MAIORKA, A. Função gastrintestinal e seu impacto no rendimento avícola. In: CONFERÊNCIA APINCO'2000 DE CIÊNCIA E TECNOLOGIA AVÍCOLAS, 2000, Campinas. Anais... Campinas: FACTA, 2000. v.2, p.161-174

MADKOUR, A.A.; MADINA, E.M.; EL-AZOUNI, O.; ABBAS, T. Smectite in acute diarrhea of children: a double-blind placebo-controlled clinical trial. Journal of Pediatric Gastroenterology and Nutrition, Philadelphia, v.17, n.2, p.176-181, 1993.

NACIONAL RESEARCH COUNCIL - NRC.

Nutrient requirements of dogs and cats. National academy press. Washington, 2006. 426p.

SÁ-FORTES, C.M.L. Valor nutricional de ingredientes energéticos e protéicos para cães. Jaboticabal: Universidade Estadual Paulista, 2005. 82p. Tese (Doutorado em Zootecnia) Universidade Estadual Paulista, 2005.

SAS INSTITUTE. Statistical analysis system: users guide. Cary, 1996.

STRICKLING, J.A.; HARMON, D.L.; DAWSON, K.A.; GROSS, K.L. Evaluation of oligosaccharide addition to dog diets: influences on nutrient digestion and microbial populations. Animal Feed Science and Technology. Amsterdam, v.86, n.2, p.205-219, 2000.

SWANSON, K.; GRIESHOP, C.M.; FLICKINGER, E. A.; BAUER, L.L.; HEALY, H.P.;DAWSON, K.A.; MERCHEN, N.R.; FAHEY JR, G.C. Supplemental fructooligosaccharides and mannanoligosaccharides influence immune function, ileal and total tract nutrient digestibilities, microbial populations and concentrations of protein catabolites in large bowel of dogs. Journal of

Nutrition, n.132, p.980-989, 2002. 